\title{
A survey of professional maturity and self-concept in the personnel of Rafsanjan University of Medical Sciences, Iran
}

\author{
Mahdavi kh, MSc ${ }^{1}$, Alinejad H, MSc ${ }^{2 *}$, Hashemi Z, MSc ${ }^{3}$, Ghorbani f, MSc ${ }^{4}$, Bazmandegan $\mathrm{MD}^{5}$ \\ 1- MSc in Management, Rafsanjan University of Medical Science, Rafsanjan, Iran. 2- MSc in Management, Rafsanjan University \\ of Medical Science, Rafsanjan, Iran. 3- Faculty Member, Rafsanjan University of Medical Science, Rafsanjan, Iran. 4- MSc in \\ Management, Payame Noor University, Tehran, Iran. 5- PhD Student, Dept. of Pharmacology, Factuly of Medicin, Mashhad \\ University of Medical Science, Mashhad, Iran.
}

\begin{abstract}
Received: May 2014, Accepted: January 2015

Background: One of the factors that can improve self-concept and performance of staff is professional maturity. Professional maturity can also solve the problems of self-concept. The purpose of this paper was to identify the relationship between the dimensions of self-concept and professional maturity.

Materials and Methods: This relative applicable study was performed on all the personnel $(n=2480)$ of Rafsanjan University of Medical Sciences, Iran, in 2013. Using Cochran's formula, 332 individuals were selected randomly as the study sample. For data collection, two questionnaires, including professional maturity and various self-concepts questionnaires were applied. Data analysis was performed using SPSS software and Spearman's rank correlation coefficient.

Results: A statistically significant relationship was observed between professional maturity and the self-concept of the personnel. Pearson's correlation coefficient and Spearman's rank correlation coefficient of the relationship between professional maturity and self-concept were 0.407 and 0.360 , respectively. Pearson's correlation coefficient and Spearman's rank correlation coefficient of collective professional maturity were 0.372 and 0.341 , respectively. The Pearson's correlation coefficient and Spearman's rank correlation coefficient of the individual self-concept were 0.305 and 0.298 , respectively.

Conclusions: There was a positive relationship between professional maturity and self-concept in the personnel of Rafsanjan University of Medical Sciences. Moreover, among the three dimensions of self-concept, the relationship dimension had a greater impact on professional maturity. Considering the influencing variables, work experience has a significant relationship with professional maturity and educational level has a significant relationship with self-concept level.
\end{abstract}

Keywords: Professional, Maturity, Self Concept, Staff.

\section{Introduction}

One of the factors which can affect the selfconcept of personnel is their professional maturity. We can apply the maturity model in order to evaluate an organization's status in terms of decision-making based on knowledge (1). This kind of maturity can be observed in the forms of individual or organizational professional maturity. Readiness, attitude, and individual abilities in performing duties can be signs of individual and professional maturity. Professional maturity is one of the basic factors in understanding the professional route, and future successful decisions. Job development is a process which has an important effect on the professional maturity of the staff in an organization (2).

\footnotetext{
* Corresponding author: Hassan Alinejad, Rafsanjan University of Medical Science, Rafsanjan, Iran.

Email: h.alinejad2012@yahoo.com
} 
Self-concept is a collection of ideas, feelings, experiences, and conscious and unconscious understanding that a person has about his/her own feelings, and, as the core of personality, plays a key role in determining what is right (3). If managers pay attention to the selfconcept as a human feature, their personnel will be more successful in understanding their own abilities and have better relationships with other workers (4). On the other hand, not understanding the self-concept correctly results in low performance and creates pressure and conflict in the organization (5). Today, one of the basic problems of every organization is organizational self-concept; thus, each manager should spend time to solve this issue. The problem of self-concept as a social phenomenon could have negative effects on the political, economical, and cultural aspects of every society. The young people in the society have the most conflicts with this phenomenon.

Based on previous studies, one of the factors which increase positive self-concept is professional maturity. A mature person can use his/her own abilities to reach his/her own goals (6). This term was first used by Super (1957) in the evolutionary theory, and could be described as the measure for a person to perform his/her own job or complete his/her own growth process. People can reach maturity in their own jobs if they are able to make sound decisions, and have enough knowledge about their jobs (7). An individual with professional maturity can find a suitable job and adapt to his/her job environment. In other words, coordination between job behavior and expected behavior is another explanation of job maturity (8).

Although the exact psychological processes are not clear, it is evident that professional maturity is affected by personal experience, education, and awareness of the workplace and employer (9). Although professional maturity can have positive outcomes in the organization, it is expected that organizational success will lead to personal success. There is a close relationship between professional maturity and self-concept. The purpose of this study was to investigate the relationship between professional maturity and self-concept of the personnel of Rafsanjan University of Medical Sciences, Iran. It also investigated the relationship between various self-concepts and professional maturity, and their relationships with factors such as age, sex, marital status, education, and occupational experience. We hope to provide valuable information for managers and experts in order to solve the existing problems in the workforce.

\section{Materials and Methods}

The subjects in this descriptive relative applicable study consisted of 2480 employees of Rafsanjan University of Medical Sciences.

From among the study population, 332 individuals were randomly chosen as samples. The Professional Maturity Questionnaire has been analyzed by Mr. Torabi in 2011. The validity and reliability of this questionnaire are 0.90 and 0.79 , respectively. The questionnaire consisted of 5 factors; 1- self-awareness, 2decision-making skills, 3- occupational knowledge, 4- a combination of self-awareness and occupational awareness, and 5occupational planning. This questionnaire consists of 18 questions and the score obtained by responders specifies their professional maturity status. The Various Self-concepts Questionnaire, designed by Selenta and Lorq (2005), has 15 questions. The questionnaire consisted of 3 factors; 1- Individual selfconcept, 2- Relationship self-concept, 3- Group self-concept. Its validity and reliability were approved by Rahimi and were 0.93 and 0.94 , respectively. Data analysis was performed using SPSS software (version 14, SPSS Inc., Chicago, IL, USA) and Pearson's correlation coefficient. All P values below 0.05 were considered significant. 


\section{Results}

In this research, of the 331 participants, 199 $(60.6 \%)$ were male and $129(39.0 \%)$ were female; $3(0.9 \%)$ did not specify their gender. Moreover, 67 individuals (20.2\%) had high school diploma, 48 (14.4\%) had associate degrees, $159(48.0 \%)$ had a bachelor's degree, $44(13.3 \%)$ had a master's degree, and 11 (3.3\%) had a $\mathrm{PhD} ; 2(0.6 \%)$ did not specify their educational level. To study the relationship between professional maturity and self-concept and to analyze the data Pearson's and Spearmen's coefficients were used. To investigate the relationship between personnel's professional maturity and self-concept of Rafsanjan University of Medical Sciences. As shown there is a correlation between professional maturity and factors of selfconcept (communication, group, individual). (Table1).

Table 1: Pearson's and Spearman's coefficients of the relationship between personnel's professional maturity and self-concept

\begin{tabular}{|c|c|c|c|c|c|c|}
\hline & $\begin{array}{l}\text { Kind of } \\
\text { relation ship }\end{array}$ & $\begin{array}{l}\text { The existence of a } \\
\text { Relationship }\end{array}$ & Number & P-value & Coefficient & $\begin{array}{l}\text { Statistical } \\
\text { coefficients }\end{array}$ \\
\hline \multirow{2}{*}{ Self-concept } & direct & + & 331 & $<0.001$ & 0.469 & Pearson \\
\hline & direct & + & 331 & $<0.001$ & 0.441 & Spearman \\
\hline \multirow{2}{*}{$\begin{array}{l}\text { Individual } \\
\text { self-concept }\end{array}$} & direct & + & 331 & $<0.001$ & 0.305 & Pearson \\
\hline & direct & + & 331 & $<0.001$ & 0.298 & Spearman \\
\hline \multirow{2}{*}{$\begin{array}{l}\text { Relationship } \\
\text { self-concept }\end{array}$} & direct & + & 331 & $<0.001$ & 0.407 & Pearson \\
\hline & direct & + & 331 & $<0.001$ & 0.360 & Spearman \\
\hline \multirow{2}{*}{$\begin{array}{c}\text { Group self- } \\
\text { concept }\end{array}$} & direct & + & 331 & $<0.001$ & 0.372 & Pearson \\
\hline & direct & + & 331 & $<0.001$ & 0.341 & Spearman \\
\hline
\end{tabular}

To compare the average of tribal opinions about self-concept and professional maturity of the staff of Rafsanjan University of Medical Sciences, demographic factors have been presented in tables 2 and 3 . As shown, there is a correlation between professional maturity and educational status, work experience, marital status, age, and gender.

Table 2: Pearson's and Spearman's coefficients of the relationship between professional maturity and gender, age, marital status, work experience, and educational level

\begin{tabular}{|c|c|c|c|c|c|}
\hline $\begin{array}{l}\text { Professional } \\
\text { maturity }\end{array}$ & $\begin{array}{l}\text { Kendall's } \\
\text { Coefficient }\end{array}$ & P-value & Number & $\begin{array}{l}\text { The existence of a } \\
\text { relationship }\end{array}$ & $\begin{array}{l}\text { Kind of } \\
\text { relationship }\end{array}$ \\
\hline Gender & 0.028 & 0.543 & 328 & - & - \\
\hline Marital status & -0.211 & $<0.001$ & 326 & + & Backset \\
\hline Age & 0.0078 & 0.129 & 326 & - & - \\
\hline Work experience & -0.242 & $<0.001$ & 320 & + & Backset \\
\hline Educational level & -0.174 & $<0.001$ & 307 & + & Backset \\
\hline
\end{tabular}


Table 3: Pearson's and Spearman's coefficients of the relationship between self-concept and gender, age, marital status, work experience, and educational level of personnel

\begin{tabular}{cccccc}
\hline $\begin{array}{c}\text { Professional } \\
\text { maturity }\end{array}$ & Kendall's Coefficient & P-value & Number & $\begin{array}{c}\text { The existence } \\
\text { of a } \\
\text { relationship }\end{array}$ & $\begin{array}{c}\text { Kind of } \\
\text { relationship }\end{array}$ \\
\hline Gender & 0.062 & 0.108 & 328 & - & - \\
\hline Marital status & -0.014 & 0.354 & 318 & + & Backset \\
\hline Age & 0.049 & 0.256 & 326 & - & - \\
\hline Work experience & -0.099 & 0.026 & 320 & + & Backset \\
\hline Educational level & -0.141 & 0.002 & 307 & + & Backset \\
\hline
\end{tabular}

\section{Discussion}

The goal of this study was to evaluate the relationship between professional maturity and self-concept of the personnel of Rafsanjan University of Medical Sciences. The results indicated a positive relationship between professional maturity and selfconcept in the participants. Maturity is a cognitive framework in which we classify the information about ourselves and process them. People usually compare their experiences with their self-concept and behave in a way that would correspond with their self-concept (10). Therefore, when selfconcept differs from experiences, a person feels out of line and the greater this inconsistency is, the more turbulence the individual feels which in turn leads to anxiety and stress (11).

One of the factors that can affect self-concept is the professional maturity is the job environment. The maturity model can be used to evaluate the organization's status in terms of knowledgeable decision-making and improve the organization's capabilities (1). Professional maturity can find its place in the organization as individual maturity. Preparedness, attitude, awareness, and personal abilities in performing organizational tasks are all indicators of professional maturity (2). Professional maturity is a basic factor in understanding the professional route and successful future decisions. Self-concept is also considered as an important aspect of a person's characteristics as it deals with individuality and differentiates an individual from others. It is a concept that makes possible the awareness of being alive, awareness of thinking, reasoning, performing special tasks, and beliefs about what a person knows about others. Individuals' self-concept is an indicator of their description of themselves or what they want to be (5)

There have been few studies in Iranian organizations about management and its role in professional maturity of their personnel. Therefore, this study aimed to investigate professional maturity and its effect on selfconcept.

The results indicated the existence of a relationship between professional maturity and self-concept in the staff of Rafsanjan University of Medical Sciences. Although few studies have been performed in this respect, the results of one study verified this relationship. Hassan (2006) has shown that professional maturity is a function of selfconcept and those who have a higher level of professional maturity have a more successful self-concept (3).

The results of other studies have also shown a relationship between professional maturity and individual self-concept. Professional maturity in the work place is an aspect of the 
responsibility of a person and involves having a scientific identity and being dependant on a culture or an ethical system. The aim of developing professional maturity is an unrelenting, cohesive, and planned effort which is worked towards improvement and modernization and remaking of the organization which results in both the improvement of the personnel's lives and organization's functions (12).

In order to reach organizational goals, professional maturity necessitates the cooperation and team work of the personnel. Self-concept is the basis for Communication behavior of individual towards the association of the organization with the environment. Research has shown that job type and ranking, and the interest of the employees all have a role in the quality and rate of the work being performed. A job which increases selfvalue creates a deep relationship between the employees, and a job that is too demanding weakens the spirits and maturity of the staff (13).

The concept of professional maturity came into view in the middle of the $20^{\text {th }}$ century in order to improve organizational reforms. The most important goals in the education of employees are professionalism, capacity building of the workers to accept new responsibilities in order to face changes, and updating knowledge. Professionalism is the most necessary requirement in the information technology era. Any negligence of this skill will undermine the competence and existence of the staff; therefore, managers should increase the self-concept and reinforce the abilities and professional competence of their staff (14).

Professional maturity is the key to professional growth among employees and leads to increased knowledge, skills, and professional attitudes (15). Cumulative identity in organizations is much more important than individual identity. This view highlights the importance of workforce management sectors (12). The improvement of professional maturity among employees results in understanding and supervising their growth. It also develops their teamwork skill. Factors which can impact professional growth and maturity are complex. Consequently, any change or improvement should begin with ideas and behaviors (16).

The results of the current study indicate that there is a relationship between professional maturity among the personnel of Rafsanjan University of Medical Sciences considering factors such as age, gender, work experience, marital status, and educational level. Variables such as gender and work experience had a significant positive relationship with professional maturity and the employees' individual characteristics. In this study, the personnel consisted of those newly joining the workforce and those with more work experience. This division had caused lower motivation for some workers and an opportunity for others to use the expertise of the older coworkers. The results of another study have also indicated a positive relationship between self-concept and variables such as age, work experience, gender, and educational level (17).

\section{Conclusion}

There is a positive relationship between professional maturity and self-concept of the personnel of Rafsanjan University of Medical Sciences. Furthermore, among the three dimensions of self-concept, the relationship dimension had a greater impact on professional maturity. In addition, work experience has a statistically significant relationship with professional maturity and educational level has a significant relationship with self-concept level. Considering the importance of professional maturity in the 
promotion of organizational profit, it seems necessary that program planners and managers pay more attention to this issue. The improvement of the abilities of personnel will lead to them gaining the skill of professional maturity and a higher selfconcept.

\section{Acknowledgment}

The authors would like to thank all the personnel of Rafsanjan University of Medical Sciences for agreeing to participate in this study.

\section{Conflict of interest: Non declared}

\section{References}

1- Mckenzie J, Winkelen CV, Grewal S. Developing organizational decision-making capability: A knowledge manager's guide. Journal of Knowledge Management 2011; 15(3):403-21.

2- Cox JM, Naomi ES. The impact of juveniles' ages and levels of psychosocial maturity on judges' opinions about adjudicative competence. law hum Behav 2012; 36(1):21-7.

3- Hekari D, Mohamadzadeh R. The assessment of adaptation rate of coronary artery disease female patients according to quadruple aspects of physiologic, self perception, role playing and independence/dependence in Tabriz, 2007-2008. Medical Science Journal of Islamic Azad University-Tehran Medical Brench 2008; 18(3):187-93.

4- Hasan B. Career maturity of Indian adolescents as a function of self-concept, vocational aspiration and gender. Journal of the Indian Academy of Applied Psychology 2006; 32(2):127-34.

5- Rahimi Nejad Z. Investigate the relationship between self-concept and contradiction of individual in employees of the Devices Executive in Rafsanajn City. [MSc Thesis]. Rafsanjan:
Islamic Azad University; 2001.

6- Shafieabadi A. Job and professional Guidance and consultations and theories about choosing a profession. Tehran: Roshd 2007; P 116.

7- Shafieabadi A. Job and education guidance (Concepts and applications). Tehran: Samt 2002; P 16-136.

8- Toraby G. Investigate the relationship between adult mental health professional and the city of Rafsanjan in executive. [MSc Thesis]. Rafsanjan: Islamic Azad University 2011.

9- Saatchi M. Functional Psychology for the mangers at home, school, organization, and society. $7^{\text {th }}$ Edition. Tehran: Virayesh 2003; P157.

10- Plucker JA, Stocking VB. Looking Outside and Inside: Self-Concept Development of Gifted Adolescents. Exceptional Children 2001; 67(4):535-48.

11- Shamlou S. Schools and theories in psychology of personality. Tehran: Roshd 1989; P 29.

12- Sparks D, loucks-Horsley S. Five models of staff development for teachers. Journal of staff development 1989; 10(4):40-57.

13- Kavousian J, kadivar p. The role of some family factors in family self-concept in high school students. Social Welfare Quartely 2006; 5(19):91111.

14- Fakhari-Ashrafi Gh. The impact of internet skill on the professional skills of Secondary shool teachers in the province of Mazandaran. Quarterly Journal of Information and Communication Technology in Educational Sciences 2013; 3(2):145-60.

15- Taheri M, Arefi M, Pardakhtchi MH, Ghahramani M. Exploring the process of professional development of teachers in teacher training centers: A grounded theory. Quarterly Journal of Educational Innovations 2013; 12(45):149-76.

16- Mortaz-Mehrabani N. How to develop the professional knowledge of mathematics teachers. [MSc Theis]. Tehran: Shaid Beheshti University; 2003.

17- Mazeedee M, Alborzee M. The relationship between childeren's self-concept and parents' child rearing style. Quarterly Journal of New Thoughts on Education 2009; 5(2):9-24. 